\title{
Article \\ Design and Characterization of a Planar Motor Drive Platform Based on Piezoelectric Hemispherical Shell Resonators
}

\author{
Frank Schiele * and Bernd Gundelsweiler $\mathbb{D}$
}

Institute of Design and Production in Precision Engineering, University of Stuttgart, 70550 Stuttgart, Germany; bernd.gundelsweiler@ikff.uni-stuttgart.de

* Correspondence: frank.schiele@ikff.uni-stuttgart.de

Citation: Schiele, F.; Gundelsweiler, B. Design and Characterization of a Planar Motor Drive Platform Based on Piezoelectric Hemispherical Shell Resonators. Actuators 2021, 10, 187. https://doi.org/10.3390/act10080187

Academic Editors: André Preumont, Haim Abramovich and Kainan Wang

Received: 14 July 2021

Accepted: 4 August 2021

Published: 6 August 2021

Publisher's Note: MDPI stays neutral with regard to jurisdictional claims in published maps and institutional affiliations.

Copyright: (c) 2021 by the authors. Licensee MDPI, Basel, Switzerland. This article is an open access article distributed under the terms and conditions of the Creative Commons Attribution (CC BY) license (https:// creativecommons.org/licenses/by/ $4.0 /)$.

\begin{abstract}
In this study, a planar ultrasonic motor platform is presented that uses three half-side excited piezoelectric hemispherical shell resonators. To understand the working principle and the harmonic vibration behavior of the piezoelectric resonator, the trajectory of the friction contact was measured in free-oscillating mode at varying excitation frequencies and voltages. The driving performance of the platform was characterized with transport loads up to $5 \mathrm{~kg}$ that also serve as an influencing downforce for the friction motor. The working range for various transport loads and electrical voltages up to $30 \mathrm{~V}$ is presented. Undesirable noise and parasitic oscillations occur above the detected excitation voltage ranges, depending on the downforce. Therefore, minimum and maximum values of the excitation voltage are reported, in which the propulsion force and the speed of the planar motor can be adjusted, and noiseless motion applies. The multidimensional driving capacity of the platform is demonstrated in two orthogonal axes and one rotary axis in open-loop driving mode, by measuring forces and velocities to confirm its suitability as a planar motor concept. The maximum measured propulsion force of the motor was $7 \mathrm{~N}$ with a transport load of $5 \mathrm{~kg}$, and its maximum measured velocity was $77 \mathrm{~mm} / \mathrm{s}$ with a transport load of $3 \mathrm{~kg}$.
\end{abstract}

Keywords: piezoelectric motor; planar ultrasonic motor; hemispherical resonator; electrode segmentation; trajectory of friction contact; laser vibrometer measurement

\section{Introduction}

Ultrasonic motors of the standing wave type use resonators made of piezoelectric ceramic materials to create propulsion force via a friction contact. The friction contact pushes at ultrasonic resonance frequency against a movable rotor or a guided slider element, and sets these in motion [1-3]. Commercially available standing wave motors typically use plate geometry for their resonators [4], since this geometry is very suitable for strong linear forward and backward motion along one axis. The downforce between the resonator and the slider can be defined by a spring [5] in this type of motor. Applications mainly include high-precision motion tasks in the submicron range, vacuum compatibility, or environments where the coil- and magnet-free working principle is beneficial; examples are shown in [6-9]. An obvious solution for high-precision multidimensional drives with high motion ranges in the $\mathrm{XY}$ and Phi directions is a stacked design consisting of two linear tables and one rotary table, comparable to the design used in [10]. In contrast, planar motors allow motion in these directions on a single stage. In the event that ultrasonic motor technology is requested for such a planar motor, either a perpendicular setup of plate resonators-as in [11,12] - is conceivable, or the resonator geometry must be changed to a type allowing multidimensional vibrations. Various concepts for composite multidimensional resonators in planar motors can be found in research publications, such as those mentioned in [13-15]. Composite resonators are composed of piezoelectric material parts as driving actuators in combination with a resonant structure made of a different material (e.g., steel [16]) that amplifies the resonant mode for driving. Metal tuning blocks can be installed in the 
structure to tune the resonance frequencies [17]. An innovative and alternative motion concept to composed resonators is shown in this paper; it uses monolithic piezoelectric resonators in the shape of a hemispherical shell to create a multidimensional propulsion force. Three of these resonators combined form a planar motor drive platform that can move in both the rotatory and translatory directions as a planar motor. Three friction contacts serve as actuating drive tappets as well as three point bearings, similar to the planar motor concepts presented in $[18,19]$. The motivation for using piezoelectric shells as actuators comes from previous structural dynamic simulations and initial experiments shown in [20]. The advantage of the monolithic piezoelectric shell structure is the simple manufacturing process and the lack of a need for tuning blocks. In [21,22], piezoelectric material simulations, the design and structure of the shell resonators are shown. This paper describes the schematic design and harmonic behavior of the planar motor prototype. The resulting propulsion forces and driving velocities in different load scenarios are examined.

\section{Materials and Methods}

An explanation of shell-based piezoelectric standing wave resonators is followed by an overview of the mechanical and electrical design of the platform.

\subsection{Ultrasonic Standing Wave Resonators Made of Piezoelectric Hemispherical Shells}

The piezoelectric shells in this paper are made of the material SONOX P5, which is a soft piezoelectric ceramic. One advantage of soft PZT is its comparatively good broadband excitability [23]; material data can be seen in Table 1 [24]. The outer diameter of the shell is $25.6 \mathrm{~mm}$, with a total height of $12.8 \mathrm{~mm}$ and a wall thickness of $2 \mathrm{~mm}$ (Figure 1 (left)). The four segments on the outer electrode are laser structured, and the insulating distance is $2 \mathrm{~mm}$. To avoid introducing unnecessary heat into the temperature-sensitive piezoelectric material, ultrashort laser pulses in the green wavelength range are used to structure the 10-micron silver outer electrode material. Ultrafast laser ablation characteristics of the PZT ceramic, along with fitting parameters, can be found in [25]. Depending on the desired direction of motion, the shell resonator is excited via the corresponding electrode segments. With an even finer segmentation of the outer electrode, even more precise control of the output direction would be possible. Due to the lower effort required for manufacturing and signal distribution, quartered segmentation was determined to be sufficient for this prototype. The internal silver layer of the shell serves as a ground electrode. A ruby-doped sapphire $\left(\mathrm{Al}_{2} \mathrm{O}_{3}\right)$ hemisphere with a diameter of $4 \mathrm{~mm}$ is glued to the center of the top of the piezoelectric shell with DP490 adhesive, and serves as a friction contact element. The resonator is glued to a PCB board, which allows signal distribution to the connector cables. The PCB board is screwed onto the motor platform via four M2 screws. The three resonators placed on the motor platform are shown in Figure 1 (right).

If two adjacent electrodes of the shell are excited at resonance frequency, harmonic FEM simulations and measurements show a superposition of radial and tangential displacement. The trajectory of the friction contact element is in the shape of an inclined ellipse, as can be seen in the exaggerated illustration in Figure 1 (center). It is assumed that the radial deflection $d_{\text {rad }}$ favors the output force $F_{\text {out }}$, while the tangential deflection $d_{\text {tan }}$ favors the output speed $v_{\text {out }}$.

Table 1. Material properties for the material of SONOX P5, extracted from [24].

\begin{tabular}{cc}
\hline Material Property & SONOX P5 (Soft Piezoceramic) \\
\hline Stiffness & $\mathrm{c}_{33} \mathrm{D}: 14.5 \times 10^{10} \mathrm{~N} / \mathrm{m}^{2} ; \mathrm{c}_{55} \mathrm{D}: 5.8 \times 10^{10} \mathrm{~N} / \mathrm{m}^{2}$ \\
$\mathrm{Q}_{\mathrm{m}}$ & 90 \\
Relative permittivity & $\mathcal{\varepsilon}^{\mathrm{S}}{ }_{11} / \varepsilon_{0}: 1220 ; \varepsilon^{\mathrm{S}}{ }_{33} / \varepsilon_{0}: 865$ \\
Charge constant & $\mathrm{d}_{33}: 450 \times 10^{-12} \mathrm{C} / \mathrm{N} ; \mathrm{d}_{31}:-180 \times 10^{-12} \mathrm{C} / \mathrm{N} ;$ \\
$\mathrm{d}_{15}: 550 \times 10^{-12} \mathrm{C} / \mathrm{N}$ \\
\hline
\end{tabular}




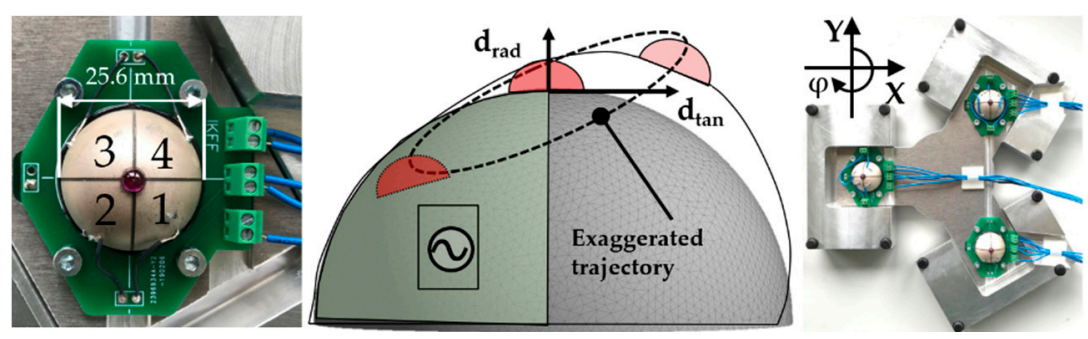

Figure 1. Hemispherical piezoelectric shell resonator for a planar motor (bottom view).

\subsection{Mechanical Design of the Planar Motor Drive Platform}

The presented prototype of the planar motor drive platform (Figure 2) was designed with isosceles triangular geometry, with three piezoelectric resonators placed on a circle with a diameter of $140 \mathrm{~mm}$. The outer dimensions were $212 \mathrm{~mm}$ in length, $244 \mathrm{~mm}$ in width, and $16 \mathrm{~mm}$ in height. The height was defined primarily by the size of the piezoelectric resonator shells. The rectangular blocks represent transport load, and serve as orientational edges for the utilized position sensor system (laser triangulation distance sensors). The planar motor platform moves on three polished ceramic plates $(100 \times 100 \mathrm{~mm})$ made of $\mathrm{Al}_{2} \mathrm{O}_{3}$ ceramic, whose geometries define the travel limit for the resonators running on it.

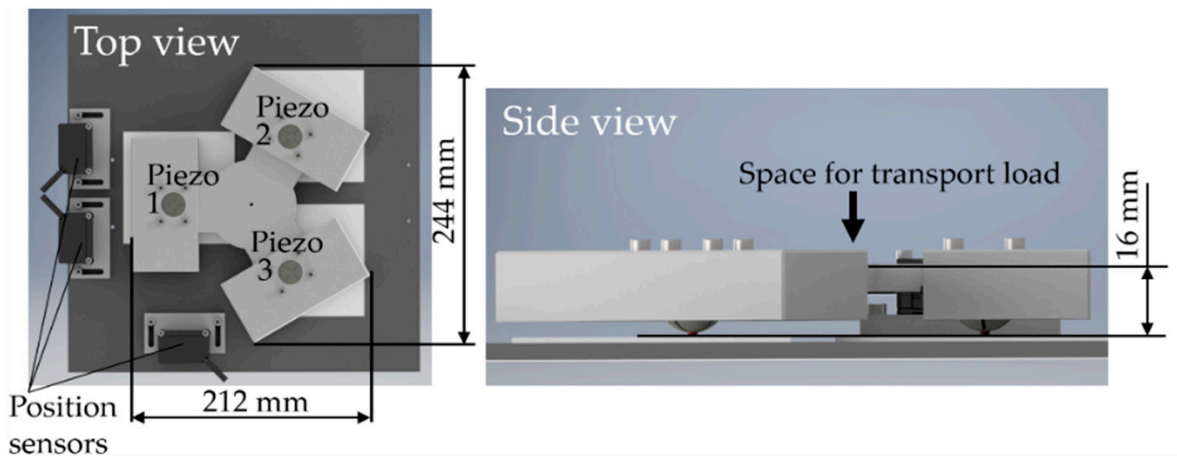

Figure 2. Design (CAD) and outer dimensions of the planar motor drive platform.

The planar motor drive platform can be controlled to drive in the directions shown in Figure 3. Depending on the actuated electrodes of the shell resonators, the resulting motion is either translatory or rotary. Especially the translatory (drive mode A,B) and the rotary motion around Piezo 1 (drive mode D) show reliable performance when used in open-loop control drive mode. These drive modes are preferred due to the appropriate alignment of the segmented resonators. The following measurements for the characterization of the planar motor are therefore performed in these axes: Precise rotation around the center of the platform (drive mode $\mathrm{C}$ ) is considered challenging, but is expected to be possible with suitable feedback position control (future development). Through finer subdivision of the electrodes than quartered division, the directions of the forces of the resonators could be made more variable and precise, in principle. This advantage comes with more effort, requiring twice the number of connectors for the electrical design of the motor.

Utilization of hard ceramic materials as friction materials is common in ultrasonic motors, and is described in [26]. In particular, it is recommended to use ceramic materials for both partners of the friction contact [27]. In our setup, the three ceramic base plates are made of the hard, wear-resistant oxide ceramic AOK01 [28], which is specified for ultrasonic motor applications. The plate $(100 \times 100 \times 3 \mathrm{~mm})$ serves as a friction contact partner to the ruby-doped sapphire $\left(\mathrm{Al}_{2} \mathrm{O}_{3}\right)$ friction element. The roughness $\mathrm{R}_{\mathrm{z}}$ specified by the manufacturer is 0.4 micrometers, and is confirmed by our measurements with a Twip OS Consigno confocal microscope. A close-up image of the plate's surface taken with 
this microscope is depicted in Figure 4. With the transport loads described in this paper for the planar motor, no visible wear on the ceramic plate surface was detected.

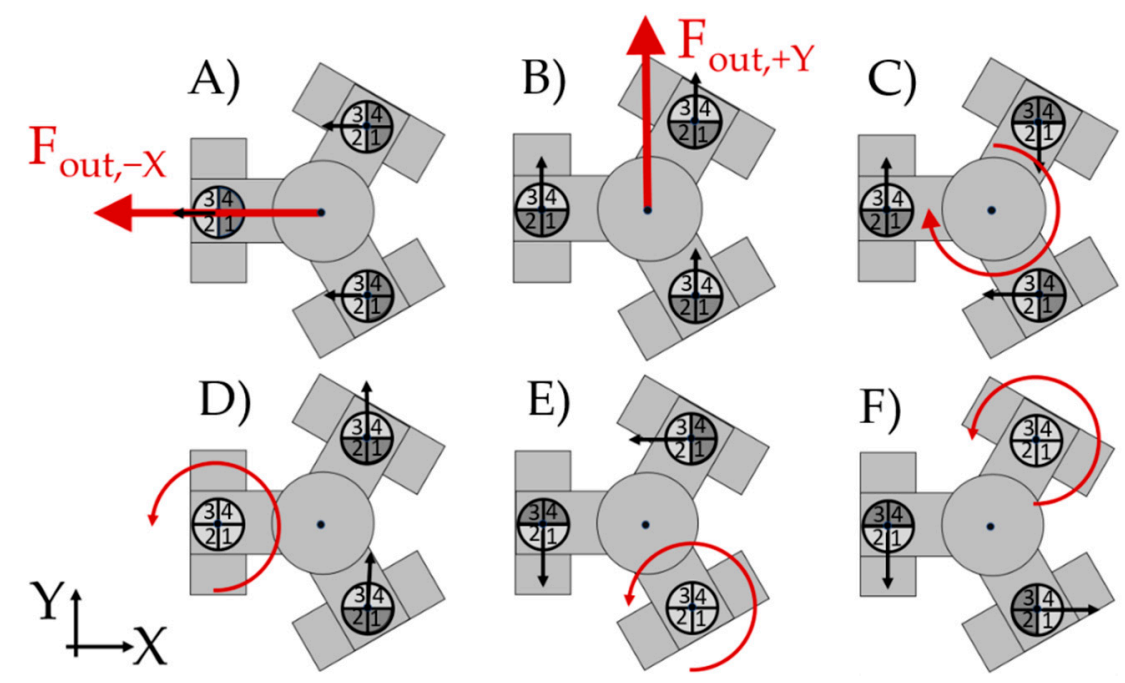

Figure 3. Motion directions of the planar motor drive platform (bottom view).

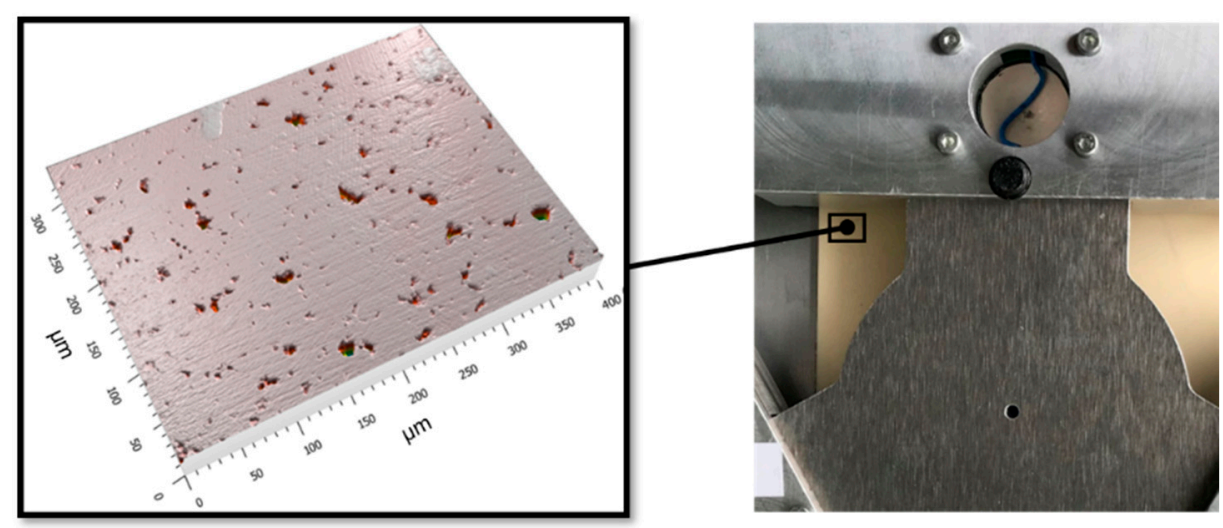

Figure 4. Magnified view of the surface of the ceramic base plate.

\subsection{Electrical Design to Control the Platform}

Real-time control of the resonators was realized via an FPGA on a dSPACE MicroLabBox microcontroller, allowing the excitation frequency $f$ and voltage amplitude A to be modulated during operation; this is necessary for the directional control of the planar motor platform. The concept for the signal generation and distribution to the electrodes is shown in Figure 5. A Simulink program running on the FPGA generates three small, independent sine signals for the three piezoelectric resonators. The generated small signals $(0-3 \mathrm{~V})$ are amplified with Rohrer PAB050 broadband power amplifiers by a factor of 10 . The high-frequency power signals ( $30 \mathrm{~V}$ amplitude) are distributed via photo MOSFET relays (KAQY212) [29] to the required electrode segments for half-sided excitation. These normally open SPST switches ensure galvanic isolation between the control signal and the amplified power signal that feed the piezoelectric resonators. With this setup, 12 electrodes can be addressed using only three HF amplifiers. Current amplitude in $30-\mathrm{V}$ piezoresonant $(85 \mathrm{kHz})$ operation is up to $350 \mathrm{~mA}$. More specific details on the control of the platform can be found in [21]. 


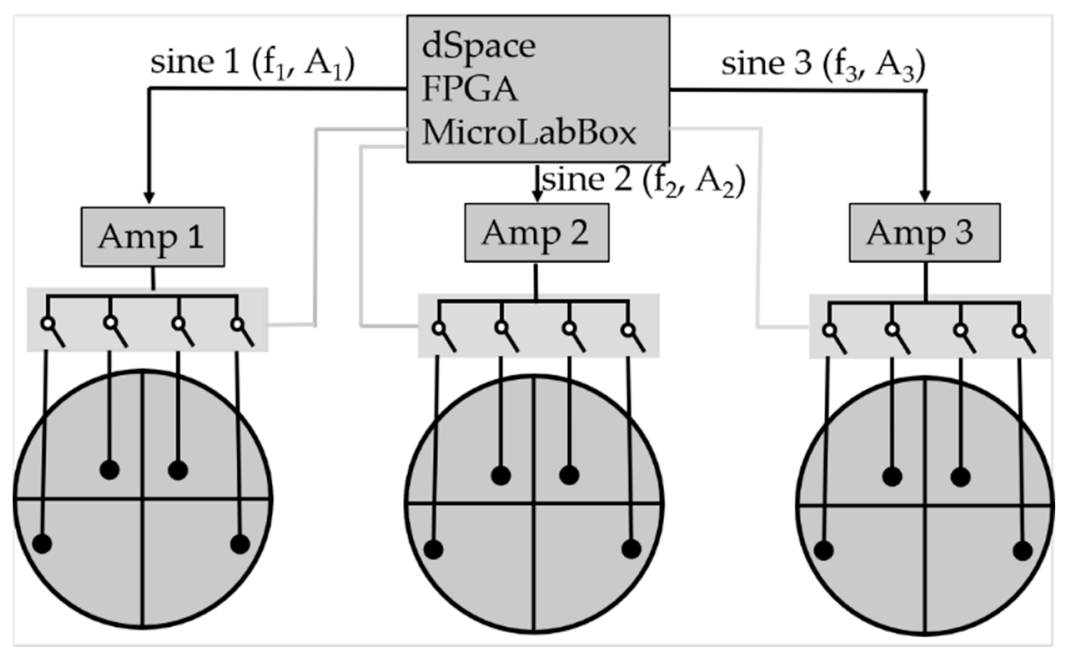

Figure 5. Signal generation and distribution to the electrodes to control the platform.

\section{Measurements and Results}

To better understand the operational principle of the resonator, measurements of displacement of the vibration at the tip of the friction contact are presented. In addition, the assembled motor drive platform is examined regarding the adjustable velocities and forces.

\subsection{Measurements of Deflection of the Friction Contact in Free-Swinging Mode}

In order to classify the dimensions of the motion trajectory of the ruby contact element on top of the piezoelectric shell, laser Doppler vibrometry [30] was used. The utilized setup is also described in [22], and is shown in Figure 6; it consists of two separate sensor heads, an out-of-plane scanning LDV head (PSV-500, Polytec, Waldbronn, Germany) to measure the radial displacement $d_{\text {rad }}$, and an in-plane LDV head (IPV-100, Polytec, Waldbronn, Germany) to measure the tangential displacement $d_{\tan }$. The measurements were performed successively. Since the LDV signal analysis controller receives the HF excitation sinus signal as phase reference information, the phases of $d_{\text {rad }}$ and $d_{\text {tan }}$ were determined. The piezoelectric hemisphere is excited on a half-side (electrodes 1 and 2), and oscillates freely without a damping contact or load on the ruby friction tip. Both lasers require a direct view of the ruby element, so the free-swinging operation without preload/damping had to be chosen. The actual vibration behavior with an opposing ceramic plate must be classified as lower due to the higher damping situation. The maximum voltage was selected at $14 \mathrm{~V}$, since higher voltages result in greater heating of the hemispherical resonator (over $70^{\circ} \mathrm{C}$ ) in the free-swinging operation.

The results of the measurements are shown in Figure 7. The measurement range covers the relevant frequency range for driving operation from 80 to $90 \mathrm{kHz}$. Measurements were conducted three times, and the average value for each frequency is shown. The resonance peaks can be clearly seen in both the out-of-plane and in-plane directions in the measured laser vibrometer data. The resonance frequency at $2-\mathrm{V}$ excitation was $85.15 \mathrm{kHz}$, and decreased to $84.4 \mathrm{kHz}$ at $14-\mathrm{V}$ excitation. This drift towards lower frequencies with higher voltage amplitudes can also be seen in admittance measurements [21], and similar observations are described in [31]. The higher strains of the shell structure at higher voltages influence the elastic behavior of the structure; this leads to the drift in the resonance frequency. Further details and explanation of this frequency drift phenomenon can be found in $[32,33]$. The calculated trajectory on the right side is a result of the measured $d_{\text {rad }}$, $\mathrm{d}_{\tan }$, and their phases. 


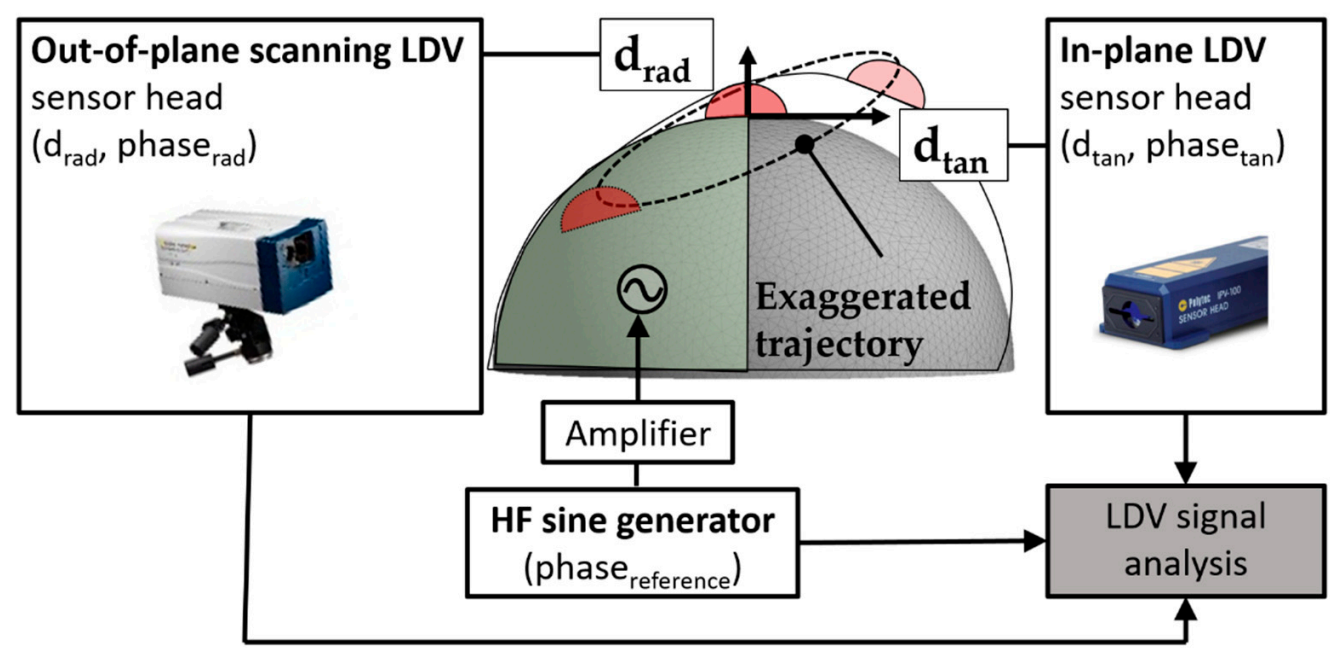

Figure 6. Laser Doppler vibrometer setup.

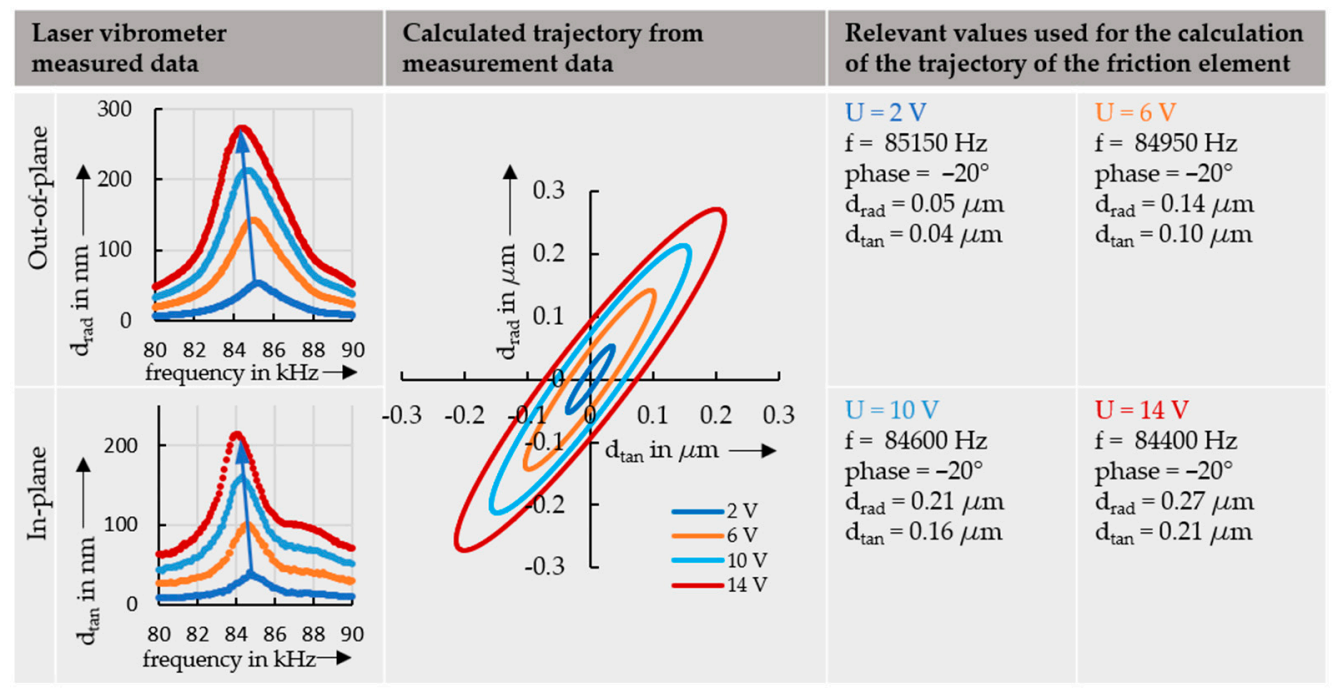

Figure 7. Measurements of radial and tangential displacement when excited half-sided (left); calculated trajectories (right).

\subsection{Measurements of the Maximum Drive Velocity}

To demonstrate the multi-axis driving behavior, measured values for the $-X$ and the $+\mathrm{Y}$ directions are presented as examples. Performances in the $+\mathrm{X}$ and in $-\mathrm{Y}$ directions are very similar to their inverted axis partners and, therefore, these measurements are not depicted. Three Micro-Epsilon optoNCD1220-50 triangulation sensors were used to determine the position and calculate the velocity using the dSPACE system. On a 50-mm travelling path along the corresponding axis, maximum velocity $\hat{v}$ was measured. For each parameter setup, three measurements were recorded, and the average value for $\hat{v}$ is shown here. The rectangular blocks above the resonators serve as weights and as edges, large enough for the position detection principle shown in Figure 8. The smallest weight selected for the presented measurements was $1620 \mathrm{~g}$, and included the resonator modules, the aluminum platform, and the rectangular blocks. The excitation frequency was $85 \mathrm{kHz}$, and the voltage varied from 0 to $30 \mathrm{~V}$ in $1-\mathrm{V}$ increments, for the half-sided excitation shown in Figure 6. These voltage settings were also tested with additional transport loads, which were placed in the center of the platform. 


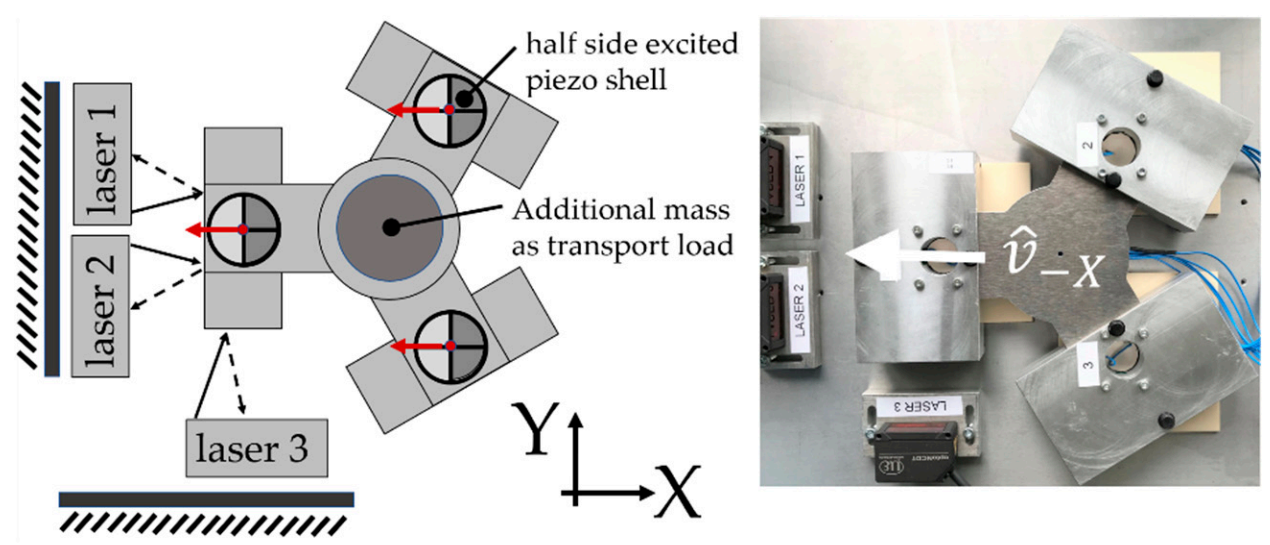

Figure 8. Setup for drive speed measurements of the planar motor platform.

\subsubsection{Velocity Measurements in the $-X$ Direction}

The results of the measurement in Figure 9 show $\hat{v}$ for the different load scenarios. If the platform is driven in drive mode $\mathrm{A}$ (Figure 3), it moves in the $-\mathrm{X}$ direction. The platform begins to move after the dead zone is passed when $U_{\min }$ is reached. The speed can then be increased by increasing $U$. After reaching $U_{\max }$, which is also characterized by audible noise, the speed no longer increases. The approximately linear range between $\mathrm{U}_{\min }$ and $\mathrm{U}_{\max }$ can thus be used to control the velocity of the motor. This is the working range that should be used by an automated control system when using this platform as a positioning system, and is shown in Table 2. By applying additional load weights, the velocity curve shifts approximately uniformly to higher electrical voltages. Noticeably, the highest travel velocity is not achieved with the lowest load weight. At a weight of $1620 \mathrm{~g}$, with voltages above $20 \mathrm{~V}$, parasite vibrations are observed, which are suspected to be due to the pronounced radial component of the trajectory of the oscillating friction tappet. The maximum velocity for $1620 \mathrm{~g}$ is $60 \mathrm{~mm} / \mathrm{s}$. The absolute maximum velocity of all tested settings is $77 \mathrm{~mm} / \mathrm{s}$, and is reached with a downforce resulting from a total weight of $3620 \mathrm{~g}$ when excited with $28 \mathrm{~V}$. The correlation between increasing electrical voltage and increasing platform velocity also fits very well with the observation in Section 3.1 of increasing trajectories at the friction contact tip as electrical voltage increases.

Table 2. Appropriate operating ranges for velocity in the $-X$ direction.

\begin{tabular}{cccccc}
\hline Total Weight & $\mathbf{1 6 2 0} \mathbf{g}$ & $\mathbf{2 6 2 0} \mathbf{g}$ & $\mathbf{3 6 2 0} \mathbf{g}$ & $\mathbf{4 6 2 0} \mathbf{g}$ & $\mathbf{5 6 2 0} \mathbf{g}$ \\
\hline $\mathrm{U}_{\min }$ & $7 \mathrm{~V}$ & $10 \mathrm{~V}$ & $13 \mathrm{~V}$ & $15 \mathrm{~V}$ & $17 \mathrm{~V}$ \\
$\mathrm{U}_{\max }$ & $19 \mathrm{~V}$ & $27 \mathrm{~V}$ & $28 \mathrm{~V}$ & $30 \mathrm{~V}$ & $30 \mathrm{~V}$ \\
$\mathrm{~V}_{-X, \min }$ & $5.7 \mathrm{~mm} / \mathrm{s}$ & $7.7 \mathrm{~mm} / \mathrm{s}$ & $8.6 \mathrm{~mm} / \mathrm{s}$ & $6 \mathrm{~mm} / \mathrm{s}$ & $5 \mathrm{~mm} / \mathrm{s}$ \\
$\mathrm{v}_{-X, \max }$ & $59 \mathrm{~mm} / \mathrm{s}$ & $61.3 \mathrm{~mm} / \mathrm{s}$ & $\mathbf{7 7 ~ \mathbf { m m } / \mathbf { s }}$ & $67.3 \mathrm{~mm} / \mathrm{s}$ & $51 \mathrm{~mm} / \mathrm{s}$ \\
\hline
\end{tabular}

\subsubsection{Velocity Measurements in the $+Y$ Direction}

When the platform is controlled to move in the $+Y$ direction (drive mode $B$ ), it results in the measurements in Figure 10. Compared to the measurements in the $-\mathrm{X}$ direction in Figure 9, velocities around $75 \mathrm{~mm} / \mathrm{s}$ can be achieved even with lower weights. The appropriate operating ranges shown in Table 3 are very similar to those in Table 2. The motor shows good driving properties along the orthogonal axes. In general, by increasing the electrical voltage within the specified working range, an increase in velocity is measured for all tested loads. This behavior is consistent with the observations of the trajectory measurements of the contact tip in Section 3.1. 


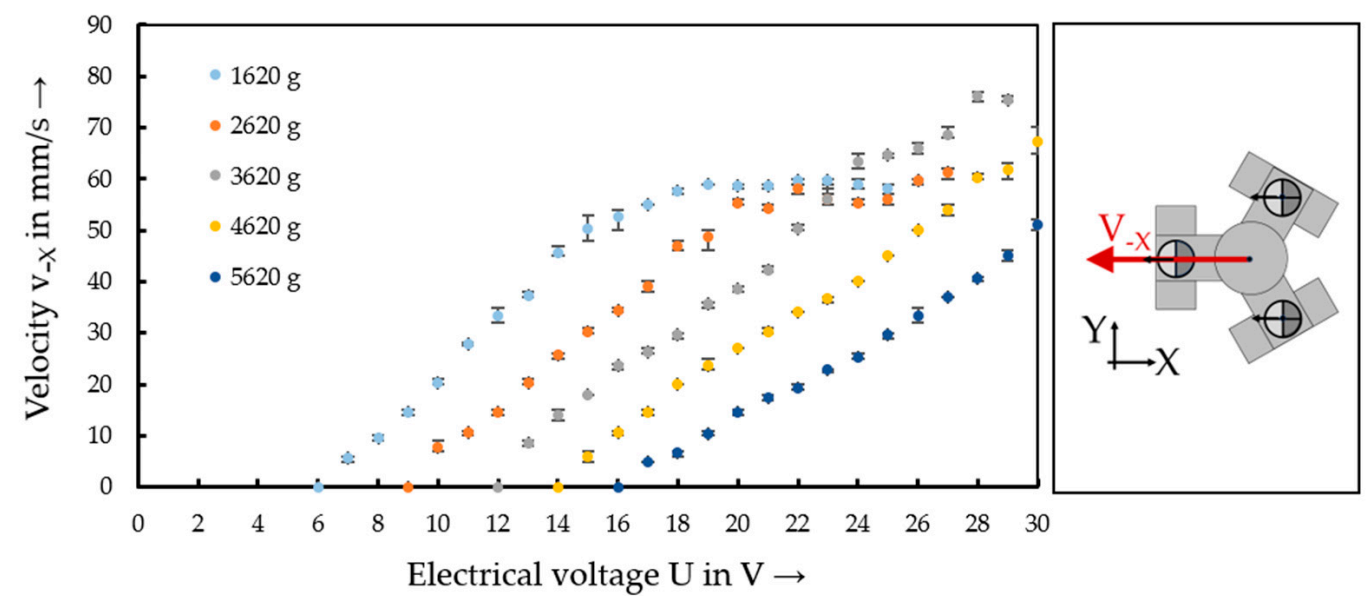

Figure 9. Measurement results of the maximum drive velocity $\hat{v}_{-X}$ of the planar motor platform in the $-\mathrm{X}$ direction for different transport load scenarios.

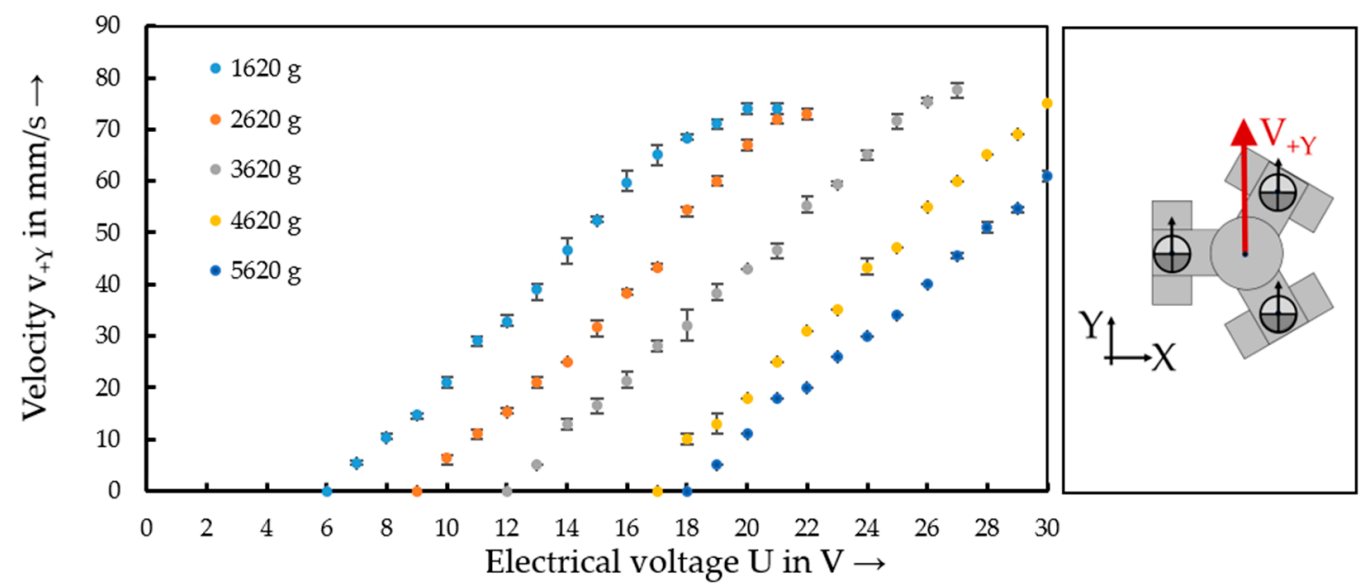

Figure 10. Measurement results of the drive velocity $\hat{v}_{+Y}$ of the planar motor platform in the $+Y$ direction for different transport load scenarios.

Table 3. Appropriate operating ranges for velocity in the $+Y$ direction.

\begin{tabular}{cccccc}
\hline Total Weight & $\mathbf{1 6 2 0} \mathbf{g}$ & $\mathbf{2 6 2 0} \mathbf{g}$ & $\mathbf{3 6 2 0} \mathbf{g}$ & $\mathbf{4 6 2 0} \mathbf{g}$ & $\mathbf{5 6 2 0} \mathbf{g}$ \\
\hline $\mathrm{U}_{\min }$ & $7 \mathrm{~V}$ & $10 \mathrm{~V}$ & $13 \mathrm{~V}$ & $18 \mathrm{~V}$ & $19 \mathrm{~V}$ \\
$\mathrm{U}_{\max }$ & $20 \mathrm{~V}$ & $22 \mathrm{~V}$ & $27 \mathrm{~V}$ & $30 \mathrm{~V}$ & $30 \mathrm{~V}$ \\
$\mathrm{~V}_{+} \mathrm{Y}, \min$ & $5.3 \mathrm{~mm} / \mathrm{s}$ & $6.3 \mathrm{~mm} / \mathrm{s}$ & $5 \mathrm{~mm} / \mathrm{s}$ & $10 \mathrm{~mm} / \mathrm{s}$ & $5 \mathrm{~mm} / \mathrm{s}$ \\
$\mathrm{V}_{+}, \max$ & $74 \mathrm{~mm} / \mathrm{s}$ & $73 \mathrm{~mm} / \mathrm{s}$ & $\mathbf{7 7} \mathbf{~ m m} / \mathbf{s}$ & $75 \mathrm{~mm} / \mathrm{s}$ & $61 \mathrm{~mm} / \mathrm{s}$ \\
\hline
\end{tabular}

\subsection{Measurements of the Output Force}

The propulsion force $F_{\text {out }}$ of the planar motor platform was measured with a Sauter FL-S50 force gauge. The platform pushes on the force gauge due to the half-sided excitation, as shown in Figure 11. Additional mass can be placed in the center of the platform, and serves as a scalable transport load. A frequency of $85 \mathrm{kHz}$ was used as excitation for all three resonators, and voltage was raised in $1-\mathrm{V}$ increments. Measurements were taken after $1 \mathrm{~s}$ of continuous pushing against the force sensor for each voltage setting, using the mean value from three force measurements. The measurements represent the sum of the driving forces of the ruby friction elements of the three shell resonators.

The results of the force measurements in the $-X$ direction (drive mode $A$ ) can be seen in Figure 12. No motion was noticed below the minimum voltage $U_{\min }$. After exceeding $\mathrm{U}_{\min }, \mathrm{F}_{\text {out },-\mathrm{X}}$ increases approximately linearly until an upper maximum value $\mathrm{F}_{\text {out, }}$ max 
is reached at $U_{\max }$. In the range of the increasing output force between $U_{\min }$ and $U_{\max }$, the motor is noiseless. This range should be used as the working range. When $U_{\max }$ is exceeded, the output force does not increase any further. Due to the excessive deflections at the tip of the friction element, parasitic oscillations occur, which also produce unwanted audible noise. The appropriate and noiseless operating ranges for the different total weights can be found in Table 4. A maximum output force of $7 \mathrm{~N}$ is reached at a transport load of $5 \mathrm{~kg}$ ( $5620 \mathrm{~g}$ total weight) by applying $30 \mathrm{~V}$ amplitude; this shows the useful potential of the drive. The disturbance forces expected on a precision positioning table like the one presented-for example, due to cable pulling and pending effects—are significantly smaller in magnitude than the achievable output forces of the platform. In general, by increasing the electrical voltage, an increase in the output force is measured for all tested loads. Again, this behavior is consistent with the observations of the trajectory measurements of the contact tip in Section 3.1, as well as the velocity measurements of the platform in Section 3.2.
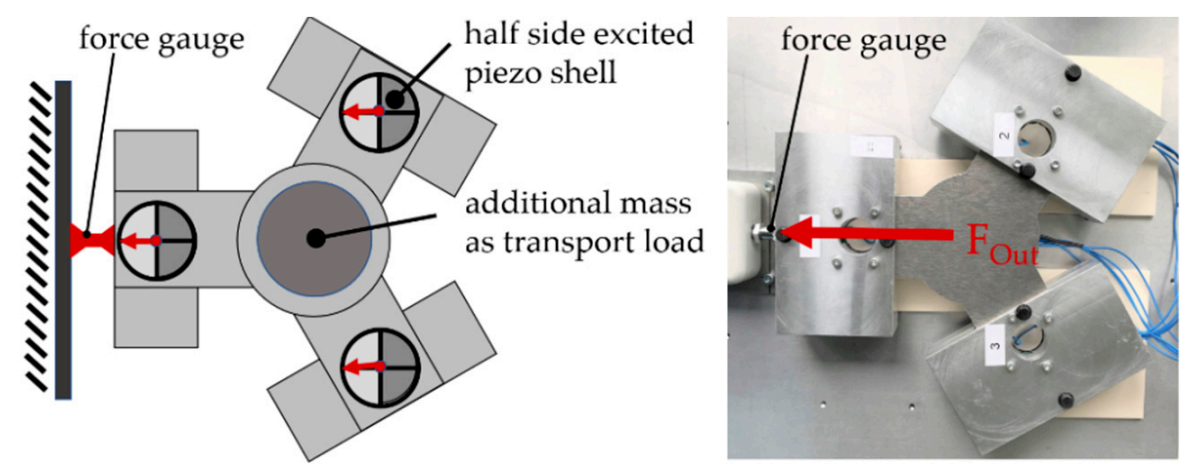

Figure 11. Setup for the output force measurements (left side: schematic bottom view; right side: top view).

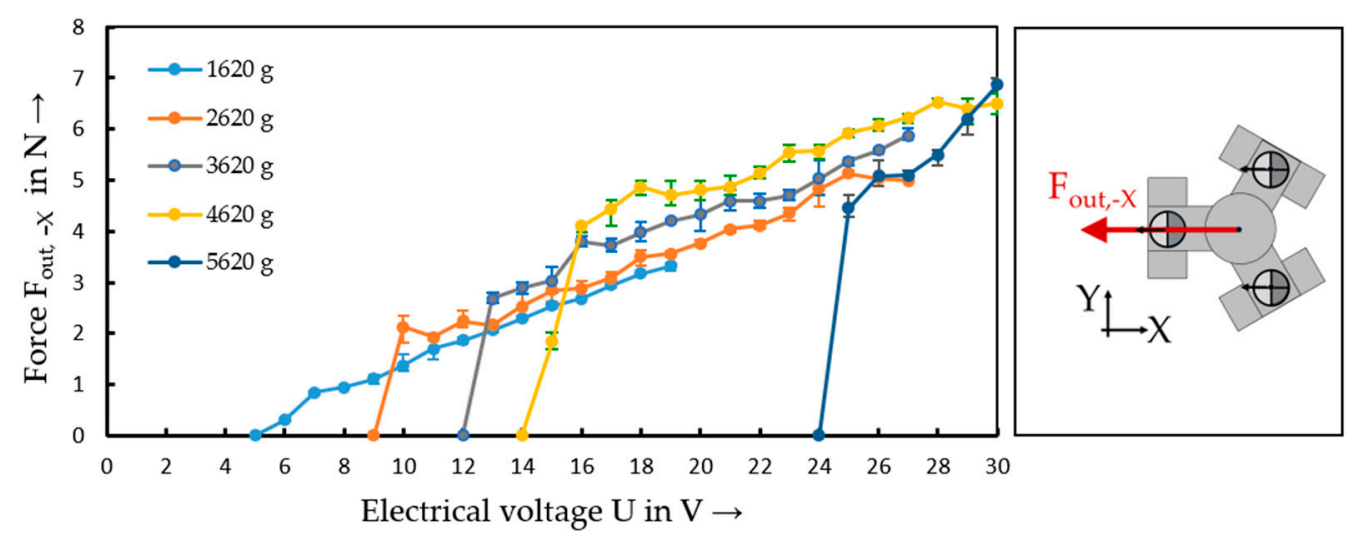

Figure 12. Measurement results of output force $\mathrm{F}_{\mathrm{out},-\mathrm{X}}$ of the planar motor platform.

Table 4. Appropriate operating ranges for force in the $-\mathrm{X}$ direction.

\begin{tabular}{cccccc}
\hline Total Weight & $\mathbf{1 6 2 0} \mathbf{g}$ & $\mathbf{2 6 2 0} \mathbf{g}$ & $\mathbf{3 6 2 0} \mathbf{g}$ & $\mathbf{4 6 2 0} \mathbf{g}$ & $\mathbf{5 6 2 0} \mathbf{g}$ \\
\hline $\mathrm{U}_{\min }$ & $6 \mathrm{~V}$ & $10 \mathrm{~V}$ & $12 \mathrm{~V}$ & $15 \mathrm{~V}$ & $24 \mathrm{~V}$ \\
$\mathrm{U}_{\max }$ & $20 \mathrm{~V}$ & $25 \mathrm{~V}$ & $27 \mathrm{~V}$ & $30 \mathrm{~V}$ & $30 \mathrm{~V}$ \\
$\mathrm{~F}_{\text {out, } \min }$ & $0.30 \mathrm{~N}$ & $2.10 \mathrm{~N}$ & $2.68 \mathrm{~N}$ & $4.10 \mathrm{~N}$ & $4.46 \mathrm{~N}$ \\
$\mathrm{~F}_{\text {out, } \max }$ & $3.53 \mathrm{~N}$ & $5.10 \mathrm{~N}$ & $6.1 \mathrm{~N}$ & $6.53 \mathrm{~N}$ & $\mathbf{7 ~ N}$ \\
\hline
\end{tabular}

When the platform is moved in the $+\mathrm{Y}$ direction (drive mode $\mathrm{B}$ ), the results of the force measurements can be seen in Figure 13. The force gauge is in line with the force vector of $F_{\text {out, } Y}$ passing through the center of the platform. The platform moves in the $+Y$ 
direction, and the upper edge of the platform pushes against the force gauge. The curves are similar to those for the $-X$ direction shown in Figure 6, and show good performance for all tested transport loads. Still, slightly weaker output forces are achieved in the $+Y$ direction. For example, the maximum output force here is $5.8 \mathrm{~N}$ at $5620 \mathrm{~g}$ and $30 \mathrm{~V}$. The reason for this is assumed to be manufacturing inaccuracies of the resonator, which can be improved. However, the achievable forces are still large enough to counteract disturbances in the range of motion. The appropriate and noiseless operating ranges for the different total transport loads can be found in Table 5 .

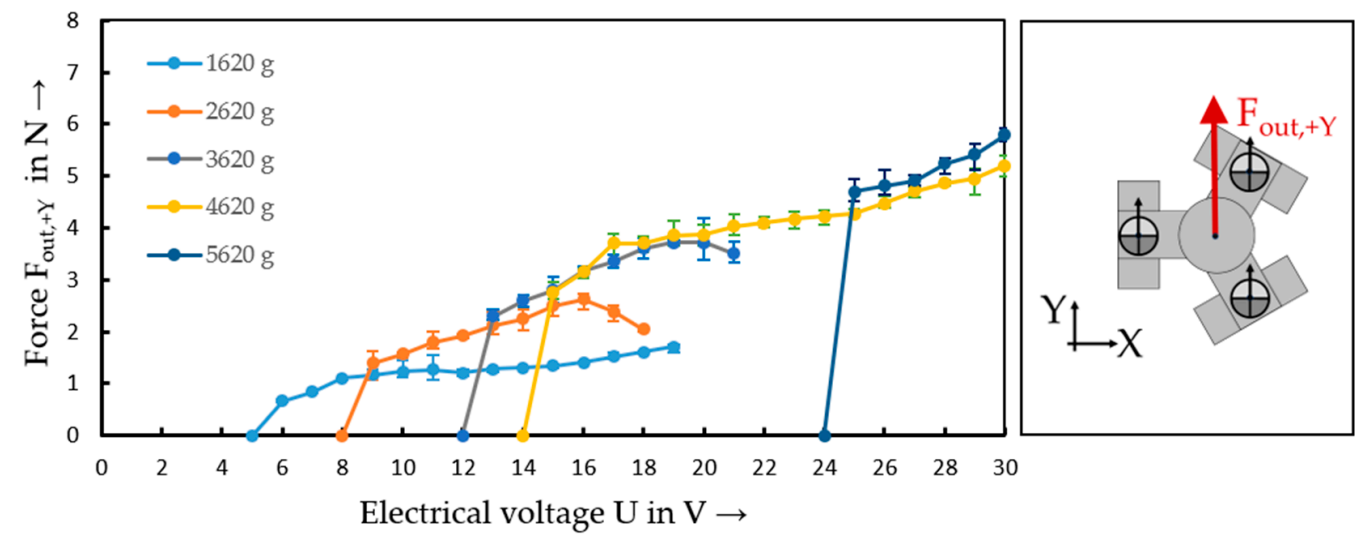

Figure 13. Measurement results of output force $\mathrm{F}_{\mathrm{out},+Y}$ of the planar motor platform.

Table 5. Appropriate operating ranges for force in the $+Y$ direction.

\begin{tabular}{cccccc}
\hline Total Weight & $\mathbf{1 6 2 0} \mathbf{g}$ & $\mathbf{2 6 2 0} \mathbf{g}$ & $\mathbf{3 6 2 0} \mathbf{g}$ & $\mathbf{4 6 2 0} \mathbf{g}$ & $\mathbf{5 6 2 0} \mathbf{g}$ \\
\hline $\mathrm{U}_{\min }$ & $6 \mathrm{~V}$ & $9 \mathrm{~V}$ & $13 \mathrm{~V}$ & $15 \mathrm{~V}$ & $25 \mathrm{~V}$ \\
$\mathrm{U}_{\max }$ & $19 \mathrm{~V}$ & $16 \mathrm{~V}$ & $19 \mathrm{~V}$ & $30 \mathrm{~V}$ & $30 \mathrm{~V}$ \\
$\mathrm{~F}_{\text {out, } \min }$ & $0.66 \mathrm{~N}$ & $1.39 \mathrm{~N}$ & $2.3 \mathrm{~N}$ & $2.76 \mathrm{~N}$ & $4.7 \mathrm{~N}$ \\
$\mathrm{~F}_{\text {out, } \max }$ & $1.7 \mathrm{~N}$ & $2.62 \mathrm{~N}$ & $3.72 \mathrm{~N}$ & $5.2 \mathrm{~N}$ & $5.8 \mathrm{~N}$ \\
\hline
\end{tabular}

When the platform is rotated around Piezo 1 (drive mode D), $\mathrm{F}_{\text {out }}$ can be measured, and the resulting torque $\tau$ from the distance of $140 \mathrm{~mm}$ to the center of rotation is shown in Figure 14. The appropriate operating ranges in Table 6 show consistent behavior for the working ranges of the translatory motions. In summary, these measurements show that the motor is functional along all axes, with well-balanced multidimensional performance, and is suitable as a planar drive.
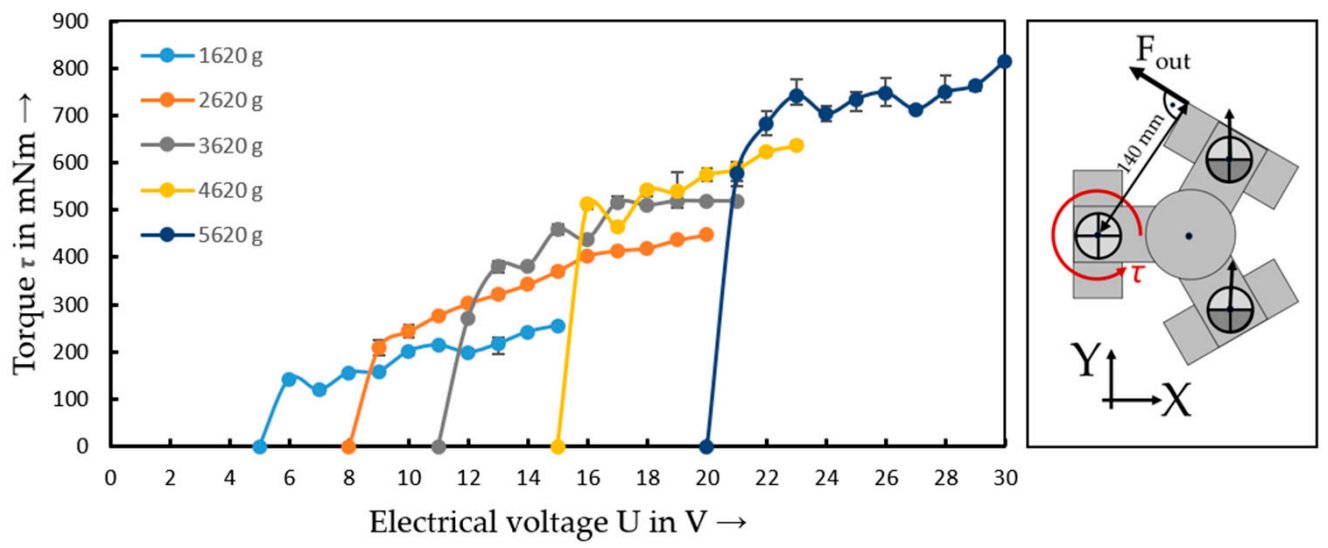

Figure 14. Resulting torque $\tau$ from rotation around Piezo 1. 
Table 6. Appropriate operating ranges for rotation around Piezo 1.

\begin{tabular}{cccccc}
\hline Total Weight & $\mathbf{1 6 2 0} \mathbf{g}$ & $\mathbf{2 6 2 0} \mathbf{g}$ & $\mathbf{3 6 2 0} \mathbf{g}$ & $\mathbf{4 6 2 0} \mathbf{g}$ & $\mathbf{5 6 2 0} \mathbf{g}$ \\
\hline $\mathrm{U}_{\min }$ & $6 \mathrm{~V}$ & $9 \mathrm{~V}$ & $12 \mathrm{~V}$ & $16 \mathrm{~V}$ & $21 \mathrm{~V}$ \\
$\mathrm{U}_{\max }$ & $15 \mathrm{~V}$ & $20 \mathrm{~V}$ & $21 \mathrm{~V}$ & $23 \mathrm{~V}$ & $30 \mathrm{~V}$ \\
$\boldsymbol{\tau}_{\min }$ & $142 \mathrm{mNm}$ & $209 \mathrm{mNm}$ & $270 \mathrm{mNm}$ & $512 \mathrm{mNm}$ & $577 \mathrm{mNm}$ \\
$\boldsymbol{\tau}_{\max }$ & $255 \mathrm{mNm}$ & $448 \mathrm{mNm}$ & $577 \mathrm{mNm}$ & $636 \mathrm{mNm}$ & $815 \mathrm{mNm}$ \\
\hline
\end{tabular}

\section{Discussion}

In this study, an innovative ultrasonic motor was presented that allows motion in both the translatory and rotary directions on a single stage as a planar motor platform, by standing and moving on three ruby friction contacts. The three resonators used were 12.8-mm-high piezoelectric hemispherical shells, which are suitable as multidimensional monolithic resonators because of their simple producibility and only small necessary modifications concerning quartered electrode structuring and ruby friction contact installation at the top. The measurement of the trajectories with the laser Doppler vibrometer setup in the freely oscillating state shows a uniform increase in both the radial and tangential displacements when the electrical voltage is increased. Due to the feasibility of the measuring principle (visual accessibility of the friction contact), the measurements in the free-swinging state must suffice at this point; these provide an initial indication of the actual vibration in drive mode, which is damped by the downforce. The resulting knowledge of the friction contact's trajectory in this vibration mode could also be used for accurately tuned FEM simulations in the future.

The performance of the motor was examined based on the data of the output force and driving velocity at different excitation voltages of up to $30 \mathrm{~V}$ at $85 \mathrm{kHz}$, and total weights of up to $5620 \mathrm{~g}$. The appropriate operating ranges (voltage range between $U_{\min }$ and $U_{\max }$ ) are shown for the respective weight class. The maximum measured output force in translatory drive mode in the $-X$ direction was approximately $7 \mathrm{~N}$ at a downforce resulting from $5620 \mathrm{~g}$ and an excitation voltage of $30 \mathrm{~V}$. The maximum measured travel speed of $77 \mathrm{~mm} / \mathrm{s}$ was achieved with a total weight of $3620 \mathrm{~g}$ and a voltage of $28 \mathrm{~V}$. The maximum operational voltage $\mathrm{U}_{\max }$ is presented for each corresponding weight load. If these values are exceeded, excessive deflections in the trajectory occur, leading to undesirable parasitic vibrations, noticeable by audible noise. The motor also shows well-balanced performance in the $+Y$ direction and along the rotational axis, and proves to be a suitable concept for an ultrasonic planar drive. Due to the monolithic resonators, the motor has a very simple mechanical design. The base weight of the platform is very light, and is mainly determined by the weight of the three resonators. Transport loads from 0 to $5 \mathrm{~kg}$ can be moved reliably, as shown in the measurements.

Ongoing research for this motor will involve investigations into its precision-positioning capability. So far, the system is still controlled in an open loop, and for precision-positioning applications, a closed-loop system is necessary. The output forces and drive velocities shown in this paper demonstrate the usability and potential of the drive concept. Improving the manufacturing process of the resonators will help ensure more similar swinging and even better control of the drive performance in all directions, which can make the platform a powerful candidate as an XYPhi motor in special environments. Applications include magnetic-field-free work environments for manufacturing, measurement, and manipulator purposes. The system can also be designed to be vacuum-compatible. The overall height dimension is very small compared to stacked positioning stages, as it is basically determined by the height of the piezoelectric shells. Miniaturized resonator designs with smaller shells are also conceivable.

Author Contributions: Conceptualization, F.S.; methodology, F.S.; software, F.S.; validation, F.S. and B.G.; formal analysis, F.S. and B.G.; investigation, F.S.; data curation, F.S.; writing-original draft preparation, F.S.; writing-review and editing, B.G.; visualization, F.S.; supervision, B.G. Both authors have read and agreed to the published version of the manuscript. 
Funding: This research was funded by the Deutsche Forschungsgemeinschaft (DFG, German Research Foundation)—438612878.

Conflicts of Interest: The authors declare no conflict of interest.

\section{References}

1. Uchino, K. Piezoelectric ultrasonic motors: Overview. Smart Mater. Struct. 1998, 7, 273-285. [CrossRef]

2. Bein, T.; Breitbach, E.J.; Uchino, K. A linear ultrasonic motor using the first longitudinal and the fourth bending mode. Smart Mater. Struct. 1997, 6, 619-627. [CrossRef]

3. Koc, B.; Uchino, K. Piezoelectric Ultrasonic Motors. In Reference Module in Materials Science and Materials Engineering; Hashmi, S., Ed.; Elsevier: Oxford, UK, 2016; Volume 36, pp. 1-24.

4. Vyshnevskyy, O.; Kovalev, S.; Wischnewskiy, W. A novel, single-mode piezoceramic plate actuator for ultrasonic linear motors. IEEE Trans. Ultrason. Ferroelectr. Freq. Control 2005, 52, 2047-2053. [CrossRef] [PubMed]

5. Kapelke, S. A Vibro-Impact Approach to Piline ${ }^{\circledR}$ Ultrasonic Motors. In Proceedings of the International Conference and Exhibition on New Actuator Systems and Applications 2021, ACTUATOR 2021 Proceedings, Online, 17-19 February 2021. Available online: https:/ / www.mdpi.com/2076-0825/10/7/148/htm (accessed on 19 May 2021).

6. Spanner, K.; Koc, B. Piezoelectric Motors, an Overview. Actuators 2016, 5, 6. [CrossRef]

7. Peled, G.; Yasinov, R.; Karasikov, N. Performance and Applications of L1B2 Ultrasonic Motors. Actuators 2016, 5, 15. [CrossRef]

8. Fischer, G.S.; Cole, G.; Su, H. Approaches to creating and controlling motion in MRI. In Proceedings of the 33rd Annual International Conference of the IEEE Engineering in Medicine and Biology Society, Boston, MA, USA, 30 August-3 September 2011; pp. 6687-6690.

9. Su, H.; Cardona, D.C.; Shang, W.; Camilo, A.; Cole, G.A.; Rucker, D.C.; Webster, R.J.; Fischer, G.S. A MRI-guided concentric tube continuum robot with piezoelectric actuation: A feasibility study. In Proceedings of the 2012 IEEE International Conference on Robotics and Automation, St. Paul, MN, USA, 14-18 May 2012; pp. 1939-1945.

10. Steinmeyer Mechatronik Dresden. Manipulatoren. Available online: https://www.steinmeyer-mechatronik.de/positioniersysteme/ standardsysteme/manipulatoren/mp53-2-1/ (accessed on 19 May 2021).

11. Yang, X.; Liu, Y.; Chen, W.; Liu, J. Sandwich-Type Multi-Degree-of-Freedom Ultrasonic Motor with Hybrid Excitation. IEEE Access 2016, 4, 905-913. [CrossRef]

12. Shen, S.-C.; Huang, J.-C. Design and Fabrication of a High-Power Eyeball-Like Microactuator Using a Symmetric Piezoelectric Pusher Element. J. Microelectromech. Syst. 2010, 19, 1470-1476. [CrossRef]

13. Woern, H.; Seyfried, J.; Fahlbusch, S.; Buerkle, A.; Schmoeckel, F. Flexible microrobots for micro assembly tasks. In Proceedings of the MHS2000, Proceedings of 2000 International Symposium on Micromechatronics and Human Science (Cat. No.00TH8530), Nagoya, Japan, 22-25 October 2000; IEEE: Nagoya, Japan, 2000; pp. 135-143, ISBN 0-7803-6498-8.

14. Devos, S.; Van de Vijver, W.; Decoster, K.; Reynaerts, D.; Van Brussel, H. A planar piezoelectric drive with a stepping and a resonant operation mode. In Proceedings of the 4th International Conference of the European Society for Precision Engineering and Nanotechnology, Glasgow, UK, 31 May-2 June 2004.

15. Zhang, J. Large-stroke piezo-actuated planar motor for nanopositioning applications. In Proceedings of the ASPE 2014 Annual Meeting, Indianapolis, IN, USA, 22-25 June 2014; pp. 105-110.

16. Yan, X.-X.; Yao, Z.-Y. Structure design and finite element analysis of a new multi-degree-of-freedom ultrasonic motor. In Proceedings of the 2015 Symposium on Piezoelectricity, Acoustic Waves and Device Applications, Jinan, China, 30 October2 November 2015; Tao, X., Ed.; IEEE: Piscataway, NJ, USA, 2015; pp. 318-321, ISBN 978-1-4799-8807-5.

17. Van Brussel, H.; Van de Vijver, W.; Volder, M.; de Devos, S.; Reynaerts, D. A Fast, High-stiffness and High-resolution Piezoelectric Motor with Integrated Bearing and Driving Functionality. CIRP Ann. Manuf. Technol. 2006, 55, 373-376. [CrossRef]

18. Chang, W.S.; Youcef-Toumi, K. Modeling of an omni-directional high precision friction drive positioning stage. In Proceedings of the 1998 IEEE International Conference on Robotics and Automation (Cat. No.98CH36146), Leuven, Belgium, 20 May 1998; Volume 1, pp. 175-180.

19. Juhas, L.; Vujanic, A.; Adamovic, N.; Nagy, L.; Borovac, B. Development of platform for micro-positioning actuated by piezo-legs. In Proceedings of the IEEE International Conference on Robotics and Automation. Symposia Proceedings (Cat. No.00CH37065), San Francisco, CA, USA, 24-28 April 2000; pp. 3647-3653. [CrossRef]

20. Keller, B. Nutzung Piezoelektrischer Gewölbestrukturen für Multidimensionale Ultraschallmotoren. Ph.D. Thesis, IKFF, Stuttgart, Germany, 2015.

21. Schiele, F.; Gundelsweiler, B. Piezo-Actuated XYPhi-Motor based on Hemispherical Resonators. In Proceedings of the IKMT Innovative small Drives and Micro-Motor Systems; 12. ETG/GMM-Symposium, Wuerzburg, Germany, 10-11 September 2019.

22. Schiele, F.; Gundelsweiler, B. Hemispherical Resonators Made of Soft and Hard Piezo Material for Planar Ultrasonic Motors. In Proceedings of the International Conference and Exhibition on New Actuator Systems and Applications 2021, Online, 17-19 February 2021. Available online: https:/ / ieeexplore.ieee.org/abstract/document/9400551 (accessed on 19 May 2021).

23. Heywang, W.; Lubitz, K.; Wersing, W.; Hull, R.; Osgood, R.M.; Parisi, J. Piezoelectricity: Evolution and Future of a Technology, 1. Aufl; Springer: Berlin/Heidelberg, Germany, 2008; ISBN 3540686800.

24. Ceramtec Company. Piezoceramic Soft Matarials Material Data; Ceramtec Company: Catalog, Germany, 2019. 
25. Di Maio, Y.; Colombier, J.P.; Cazottes, P.; Audouard, E. Ultrafast laser ablation characteristics of PZT ceramic: Analysis methods and comparison with metals. Opt. Lasers Eng. 2012, 50, 1582-1591. [CrossRef]

26. Wallaschek, J. Contact mechanics of piezoelectric ultrasonic motors. Smart Mater. Struct. 1998, 7, 369-381. [CrossRef]

27. Ishii, T.; Matsuo, E.; Nakamura, K.; Ueha, S.; Ohnishi, K. Characteristics of Ultrasonic Motors Driven in a Vacuum. Jpn. J. Appl. Phys. 1998, 37, 2956-2959. [CrossRef]

28. Corporation, W.U.M. Wischnewskyi Ultrasonic Motors Corporation. Available online: http://wumotors.ca/ultrasonic-motorfriction-rail.html (accessed on 6 July 2021).

29. Cosmo Electronics Corp. KAQY212 Series: Solid State Relay-MOSFET-Output; Data Sheet, Docment No. 69M00001.8. Available online: http:/ / www.cosmo-ic.com/object/products/KAQY212.pdf (accessed on 19 May 2021).

30. Rothberg, S.J.; Allen, M.S.; Castellini, P.; Di Maio, D.; Dirckx, J.J.J.; Ewins, D.J.; Halkon, B.J.; Muyshondt, P.; Paone, N.; Ryan, T.; et al. An international review of laser Doppler vibrometry: Making light work of vibration measurement. Opt. Lasers Eng. 2017, 99, 11-22. [CrossRef]

31. Karpelson, M.; Wei, G.-Y.; Wood, R.J. Driving high voltage piezoelectric actuators in microrobotic applications. Sens. Actuators A Phys. 2012, 176, 78-89. [CrossRef]

32. Priya, S.; Viehland, D.; Carazo, A.V.; Ryu, J.; Uchino, K. High-power resonant measurements of piezoelectric materials: Importance of elastic nonlinearities. J. Appl. Phys. 2001, 90, 1469-1479. [CrossRef]

33. Woollett, R.S.; Leblanc, C.L. Ferroelectric Nonlinearities in Transducer Ceramics. IEEE Trans. Son. Ultrason. 1973, 20, 24-31. [CrossRef] 